\title{
Echocardiographic Parameters in Short-Normal Children Treated with Recombinant Growth Hormone (rGH)
}

Sergio Bernasconi, Cecilia Volta, Claudio Cavalli, Lorenzo Lughetti, Aldo Agnetti, Lucia Ghizzoni and Mauro Costa Department of Pediatrics, University of Parma, Parma, Italy

\section{Introduction}

Chronic growth hormone (GH) excess in adults is associated both with hyperkinetic syndrome (1) and hypertension with subsequent worsening of cardiac performance resulting in a higher morbidity and mortality for cardiac diseases (2).

In pediatric series, published data, mainly concerning GH deficient children, describe normal echocardiographic parameters in children and young adults treated with recombinant growth hormone (rGH) $(3,4)$.

In order to identify the possible effects on cardiac morphology of rGH therapy in children, we report the preliminary data of $18 \mathrm{rGH}$ treated short-normal subjects evaluated by echocardiography at our clinic.

\section{Patients and Methods}

Eighteen patients ( 9 males and 9 females) entered the study. The inclusion criteria have been: -short normal children (normal birth weight and no dysmorphic features); -prepubertal at the beginning of treatment; -rGH treatment for at least 12 months. The patients' age at the time of the cardiac study ranged from 10.3 to 14.6 years (12.5 \pm 1.8 years; mean $\pm \mathrm{SD}$ ) and they have been treated with $\mathrm{rGH}$ for

Correspondence: Dr. Sergio Bernasconi, Via Gramsci 14, 43100, Parma Italy
12 to 39 months $(23.6 \pm 10.7)$ at a mean dose of $0.73 \pm 0.12 \mathrm{IU} / \mathrm{kg} /$ week. The mean total dose has been $72.2 \pm 40.3(28-149) \mathrm{IU} / \mathrm{kg}$.

The echocardiographic evaluations were performed by using a Vingmed CFM700, which allows both the echocardiographic and the echo Doppler evaluation. The children were studied by M-mode and 2D echocardiography in left-lateral position; according to the thorax anatomy a $3.5 \mathrm{MHz}$ or a $5 \mathrm{MHz}$ transducer was used. Measurements were performed just below the mitral valve leaflets, according to the recommendations of the American Society of Echocardiography (ASE). Cardiac parameters were calculated by the dedicated software resident inside the machine, while the statistic analysis was performed on an IBM-compatible personal computer by Statgraphics, a specific software for DOS operative system.

\section{Results}

The main echocardiographic parameters i.e. left ventricular posterior wall thickness $(\mathrm{LVPW})(8.2 \pm 1.3 \mathrm{~mm}$, range $=6-10 \mathrm{~mm})$, enddiastolic septum thickness (STd) $(8.2 \pm 1.8 \mathrm{~mm}$, 6-11), end-diastolic left ventricular diameter (LVDd) (37.3 $\pm 3.3 \mathrm{~mm}, 32-46)$ and aortic root (Ao) $(24.5 \pm 2.3 \mathrm{~mm}, 19-27)$, corrected for the subjects' body surface area (BSA), were within the $95 \%$ confidence limits for the mean values 


\section{Bernasoconi et al.}

of normal population in all but one subject. $(5,6)$. The patients' left ventricular mass (LVM), calculated by the ASE-corrected formula, showed the same distribution as well. Statistical analysis showed a significant positive correlation between the total GH dose and some important cardiac parameters, i.e. STd and Ao $(\mathrm{P}<0.05)$, LVDd and LVM $(\mathrm{P}<0.01)$. Moreover these correlations are stronger than the one with BSA when analyzed by a stepwise variable selection.

\section{Discussion}

From these preliminary results it appears that the patients' data are within the normal limits except in one individual, confirming previous results $(3,4)$.

However we cannot exclude the possibility that higher doses of $\mathrm{rGH}$, as now recommended in Turner syndrome, or more prolonged periods of treatment might stimulate cardiac growth even beyond the normal limits, in keeping with the correlations we found.

Furthermore, the only patient with STd, LVDd and LVM values above the normal limits was the one who received the highest total dose of $\mathrm{rGH}$. In conclusion, the relationship between the total rGH dose and several echocardiographic parameters in short-normal children indicate the need for a careful longitudinal follow-up of patients on rGH treatment, especially considering the presence of abnormal STd and LVDd values in the child on the highest total GH dose. This surveillance is particularly warranted in the patients on the highest rGH doses such as Turner syndrome and short-normal subjects.

\section{References}

1. Thusen L, Christiensen SE, Weeke J, Orskov H, Henningsen P. A hyperkinetic heart in uncomplicated active acromegaly. Acta Med Scand 1988; 223: 337-43.

2. Csanady M, Gaspar L, Hogye M, Gruber N. The heart in acromegaly: an echocardiographic study. Int J Cardiol 1983; 2: 349-61.

3. Rowland TW, Morris AH, Biggs DE, Reiter EO. Cardiac effects of growth hormone treatment for short stature in children. J Pediatr Endocrinol 1991; 4: 19-23.

4. Barton JS, Cullen S, Hindmarsch PC, Brook CGD, Preece MA. Growth hormone treatment in idiopathic short stature: a preliminary analysis of cardiovascular effects. Acta Paediatr 1992; (suppl) 383: 35-8.

5. Henry WL, Ware J, Gardin JM, Hepner SI, McKay J, Weiner M. Echo-cardiographic measurements in normal subjects. Growthrelated changes that occur between infancy and early adulthood. Circulation 1978; 57: 278-85.

6. Lange L, Fabecic-Sabadi V, Bein G. Comparative review of normal echocardiographic values from premature infant to the adolescent. Herz 1983; 8: 105-21. 